\title{
ANGIOGRAPHY OF THE NORMAL OPHTHALMIC ARTERY AND CHOROIDAL PLEXUS OF THE EYE*
}

\author{
BY \\ P. H. SCHURR \\ From the Department of Neurosurgery, Radcliffe Infirmary, Oxford
}

THE ophthalmic artery is nearly always visible for at least part of its course in lateral carotid arteriograms. It is not generally recognized, however, that the choroidal plexus of the eye can also be demonstrated by means of angiography.

The angiographic appearances of these structures have been studied in films made with the rapid serial apparatus devised by Schuster and Curtis (Curtis, 1949). This machine is capable of producing 25 radiograms of the skull at intervals of $\frac{1}{2}, \frac{2}{3}$, or 1 second. A more comprehensive picture of the cerebral circulation can thus be obtained than by the usual technique in which films are exposed 2,4 , and 8 seconds after beginning the injection of contrast substance. The percutaneous technique was employed, and $10 \mathrm{ml} .35$ per cent. diodonet were injected into the common or internal carotid artery in the neck.

Serial films of seventeen patients showing normal angiograms, and four with obstructed cerebral circulation, were examined; in all of them the ophthalmic artery was visible. This artery is seen to arise from the internal carotid as it emerges from the cavernous sinus close to the anterior clinoid process (Figs 1, 2, and 3). The main trunk of the ophthalmic artery is considerably larger than any of its branches, including the lacrimal and supra-orbital, a point which is not always clear in text-book diagrams. The artery pursues a slightly tortuous course, largely on account of the freedom of movement which must be allowed to its branches in order to permit rotation of the eyeball. It is unlikely, therefore, that displacements by space occupying lesions within the orbit would be easy to detect.

Only a few of the branches of the artery are discernible in most arteriograms. The supra-orbital artery can occasionally be found in angiograms, and more often the terminal nasal branch can be seen anastomosing with the facial artery. The frontal branches of the ophthalmic artery can sometimes be seen, but the remaining vessels are too numerous for identification even though they may be visible.

The ophthalmic artery was found to fill less than half a second

* Received for publication March 21, 1951.

+ Pyelosil Glaxo. 


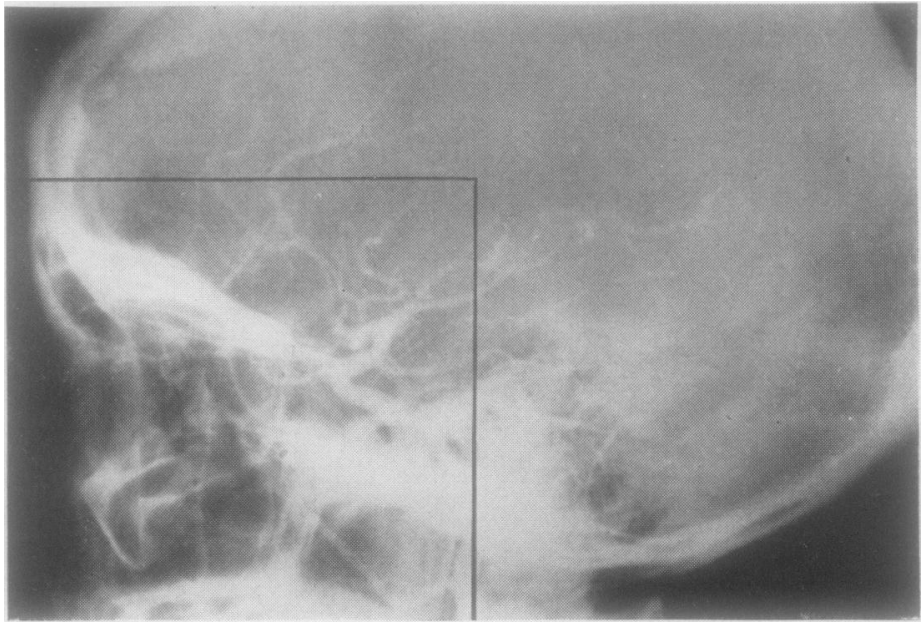

FIG. 1.--Lateral arteriogram $\left(1 \frac{1}{3} \mathrm{sec}\right.$.) showing the ophthalmic artery and the cerebral branches of the internal carotid artery. The portion illustrated in the next figure is indicated.

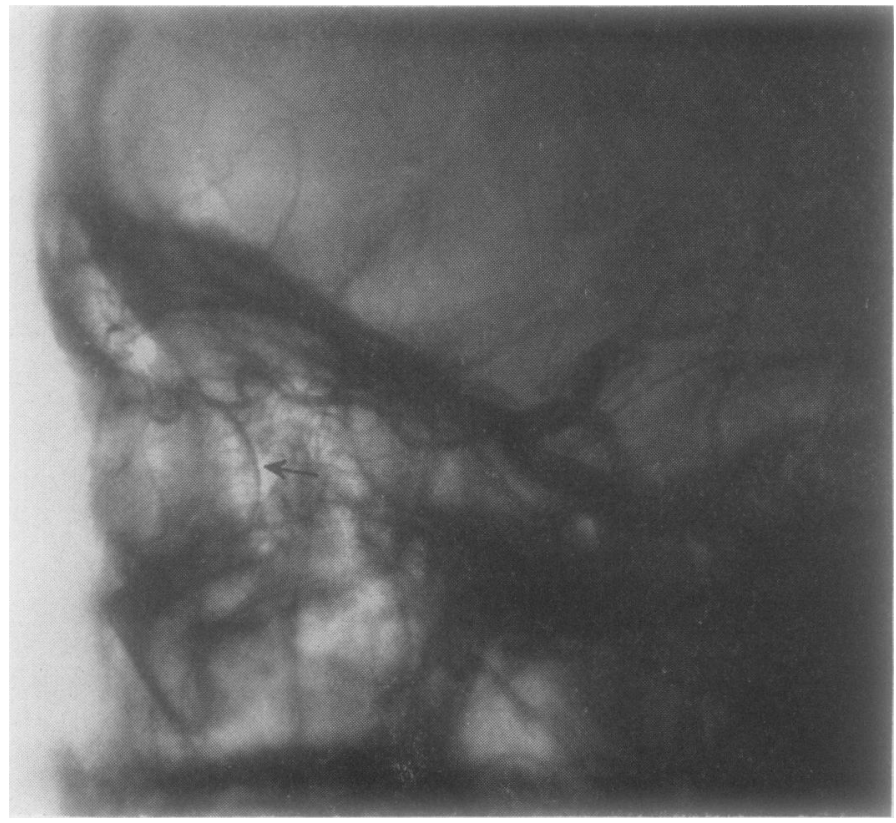

FIG. 2.- Lateral angiogram $\left(5 \frac{1}{3} \mathrm{sec}.\right)$. Part of a later frame from the same serial film as Fig. 1 showing the ophthalmic artery and the choroidal plexus of the eye (arrow). 
later than the carotid siphon, and to remain filled for half a second after the larger artery had emptied. The average duration of filling was from $1 \%$ to $2 \frac{1}{3}$ seconds after the start of the injection. Whitnall (1932) observed that the lumen of the internal carotid artery decreased in size beyond the origin of the ophthalmic artery, and this is confirmed in the majority of arteriograms, although sometimes the narrowing does not take place until just before the carotid artery joins the circle of Willis. It was suggested by Whitnall that this narrowing helps to deflect the blood stream into the ophthalmic artery, which is given off in a direction opposite to that of the carotid blood stream. The rapidity with which the ophthalmic vessels fill is clear from serial angiograms.

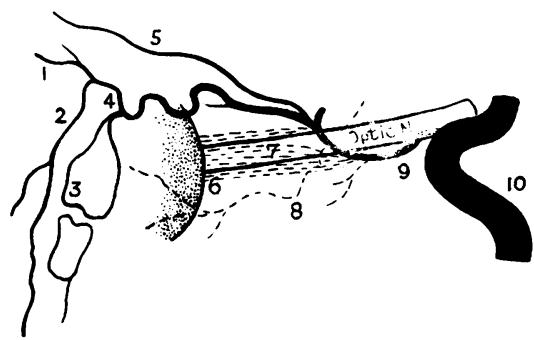

FIG. 3.-Diagrammatic interpretation of Fig. 2.

(1) Frontal branches

(2) Nasal branches

(3) Tarsal arcade

(4) Internal palpebral branches

(5) Supra-orbital artery

(6) Choroidal plexus
(7) Anterior and posterior ciliary arteries erior ciliary arteries (approximate course)

(8) Lacrimal artery (approximate course)

(10) Internal carotid
(9) Ophthalmic artery

The choroidal plexus of the eyeball was seen in ten of the seventeen normal films examined. It takes the form of a thin crescent in the outer twothirds of the orbit (Figs 2 and $3)$. The average time at which this becomes visible is 2 seconds after the beginning of the injection into the carotid artery in the neck, and it remains visible for an average of $3 \frac{1}{2}$ seconds. The first part to fill, when this can be observed, is always above the meridian of the globe. It seems that the plexus shadow is cast mainly by venous channels since it usually

begins to appear when the ophthalmic artery is fading, and stays filled during the venous phase of the cerebral circulation (Fig. 4, overleaf). The relation between these two is variable, but in most cases the choroidal plexus had disappeared by the middle of the

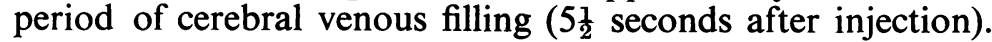

It will be seen, therefore, that these appearances are not very likely to be missed by the usual series of films taken 2,4 , and 8 seconds after the beginning of the injection. However, recognition is not easy, and it is often only by watching the gradual arrival and disappearance of the contrast shadow in serial films that these fine vessels can be distinguished from the outlines of the bone which overlies them.

It seems that the orbital vessels are more clearly seen when there is an obstruction of part of the cerebral circulation. In three cases of thrombosis of the middle cerebral artery, the choroidal plexus of 


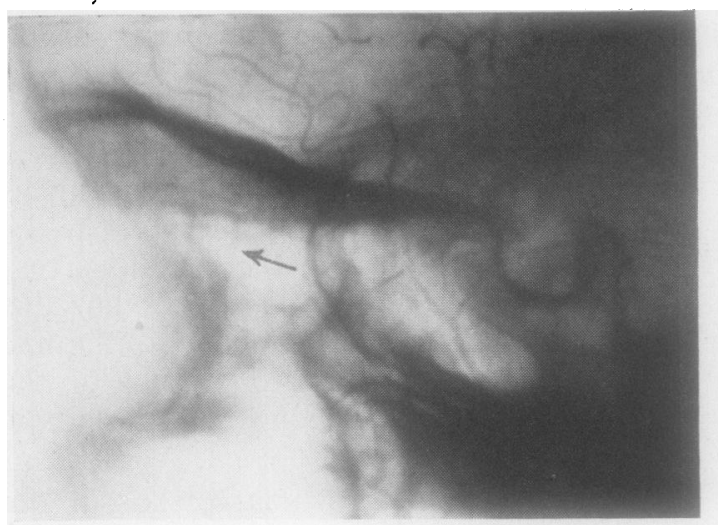

A. $2 \frac{1}{2}$ seconds after injection of contrast.

B. 6 seconds after injection of contrast.
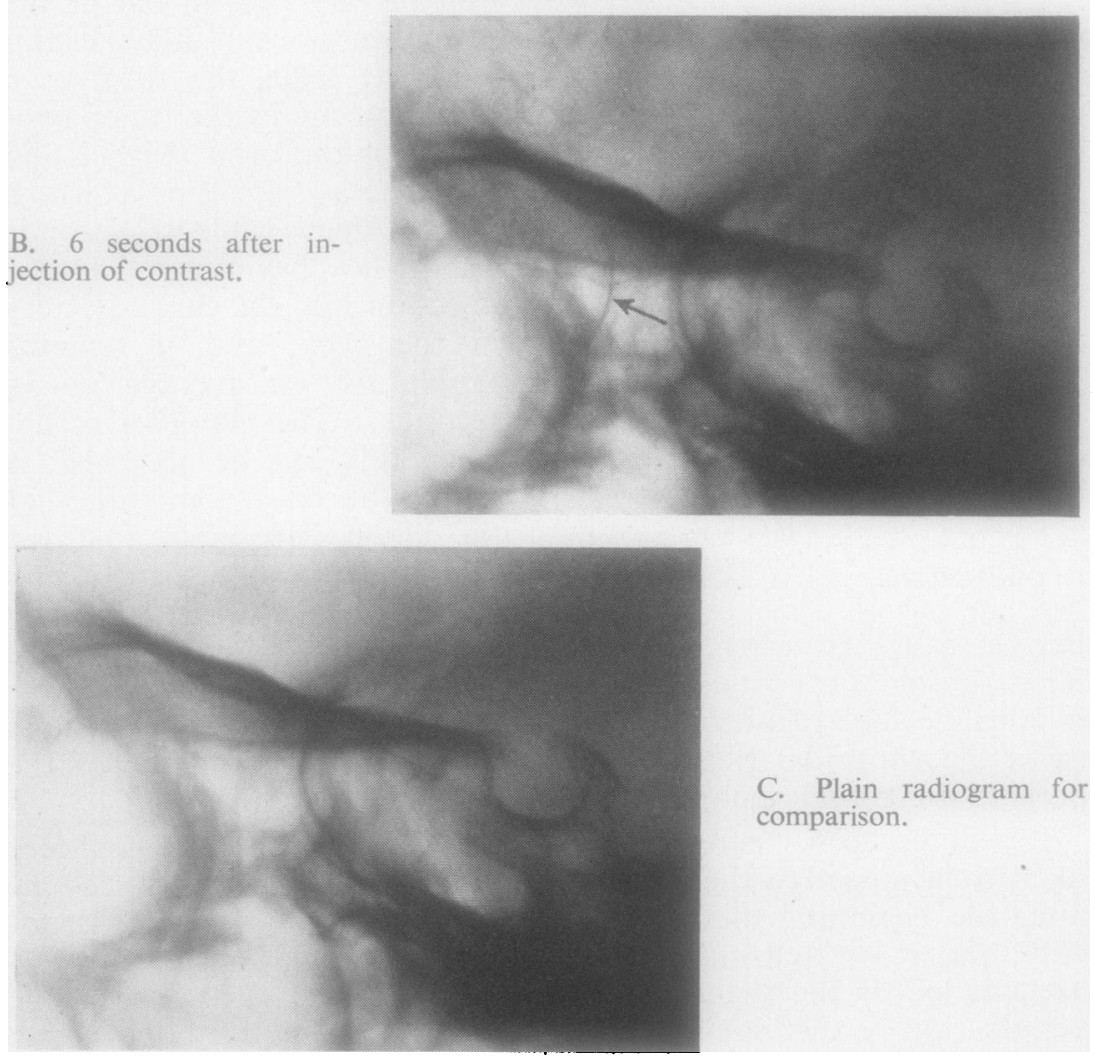

C. Plain radiogram for comparison.

Fig. 4.-Part of three frames from a normal serial angiogram, showing stages in the filling of the choroidal plexus (arrow).

In this case the circulation time in the orbit was a little slower than the average time taken in the ten normal cases in which the choroidal plexus was seen. 
the eyeball was clearly demonstrated. Another patient with a jugular thrombosis showed a normal arteriogram for the first 2 seconds, after which the anterior cerebral artery suddenly ceased to fill, presumably on account of pressure changes in the circle of Willis or a temporary spasm as there were no after effects, and at the same moment the orbital vessels became more distinct (Figs 1 and 2).

When diodone enters the circulation of the eye, it causes an intense burning pain for the duration of its stay there; this may rarely be accompanied by a flash of light. This pain is a useful indication of the successful passage of contrast into the cerebral vessels. It seems that diodone stimulates the perivascular sympathetic plexus, for the injection is followed by dilatation of the pupil. When the diodone is injected into the common carotid, thus filling the branches of the external as well as the internal carotid, the pain in the eye is sometimes obscured by simultaneous pain in the face. If the external carotid vessels are filled there is blanching of the skin of the face, followed by intense flushing, though sometimes the flush alone is seen; there is also temporary injection of the conjunctiva.

Ophthalmoscopic examination of the fundus during angiography may show momentary blanching of the arteries followed by an increase in the blood flow, comparable with the flush seen in the face. The fact of the ability of pial arteries to contract is now established (Forbes and Wolff, 1928; Penfield, 1932), and, among the earlier workers on this subject, Hirschfelder (1915) compared the reactions of the retinal and pial arteries to drugs. He found that active vasoconstriction occurred in both pial and retinal arteries after the injection of adrenaline. Whatever may be the mechanism of these effects, it follows that examination of the fundus may shed some light on the reaction of cerebral vessels to the intra-arterial injection of diodone and other contrast substances. One case (R.I. 102582/49) in which there was an unusual ocular response to diodone was recently reported by Curtis (1951).

\section{CASE RePORT}

The patient, a man of 67 , with a history of coronary thrombosis and weakness and paraesthesiae of the left hand, suffered a focal seizure involving the left side of the body after the injection of $10 \mathrm{ml} .35$ per cent. diodone into the right common carotid artery. Later the same day he observed some impairment of vision in the right eye. Ophthalmological examination showed this to be due to spasm of the right retinal

artery. After treatment with subconjunctival injections of acetyl choline $(0.5 \mathrm{ml}$. of 0.1 per cent. solution) there was some recovery of vision, but a central scotoma has remained.

Angiography of the orbital structures is a field which is largely unexplored and deserves the attention of ophthalmologists and radiologists. Apart from the more obvious application of the 
method to the depiction of vascular abnormalities, it is possible that a technique could be developed which would also be of use in the demonstration and differential diagnosis of orbital and ocular neoplasms.

\section{SUMMARY}

The angiographic appearances of the ophthalmic artery and the choroidal plexus of the eye are described, with a note on some aspects of the physiology of the ocular circulation.

I am very grateful to Sir Hugh Cairns for his helpful criticism of this paper. I should also like to thank Miss A. J. Arnott for drawing the diagram.

\section{REFERENCES}

CURTIS, J. B. (1949). J. Neurol. Neurosurg. Psychiat., 12, 167. (1951). Brit. J. Surg., 38, 295.

Forbes, H. S., and Wolfr, H. G. (1928). Arch. Neurol. Psychiat., Chicago, 19, 1057. HirschFelder, A. D. (1915). J. Pharmacol., 6, 597. Quoted by Forbes and Wolff, p. 1081 .

Penfield, W. (1932). Arch. Neurol. Psychiat., Chicago, 27, 30.

Whitnall, S. E. (1932). "The Anatomy of the Human Orbit". 2nd ed., p. 303. Oxford University Press, London. 